\title{
A criança e a cidade: contribuições da Geografia da Infância
}

\author{
The child and the city: contributions from Childhood Geography \\ El niño y la ciudad: contribuciones de la Geografía de la Infancia
}

\author{
JADER JANER MOREIRA LOPES* \\ MARIA LIDIA BUENO FERNANDES**
}

\begin{abstract}
RESUMO
Este texto aborda as crianças e seus espaços cotidianos, mais especificamente o espaço de suas vidas nas cidades. Dialogando com autores que abordam a interface criança, infâncias e espaços urbanos, busca trazer contribuições da Geografia da Infância para o tema, reconhecendo o espaço como indissociável da vida e refutando a lógica que tem colocado as trajetórias humanas na Terra como caminhos lineares e em sequência temporal cronologicamente concebida. A concepção de espaço geográfico como expressão construída na vida e de onde a vida se origina, abarca o universo infantil e o coloca dentro desse processo dialético. Assim, falar em Geografia da Infância, ler a infância, tendo como viés de entrada esse encontro que o espaço geográfico perrmite, é, para além de um significativo encontro geracional, assumir as crianças com suas potenciais presenças e como sujeitos explícitos de enunciações no espaço e no tempo, inseridas nas dimensões política, simbólica e material das sociedades.
\end{abstract}

Palavras-chave: Crianças. Infância. Cidades. Geografia da Infância.

\begin{abstract}
This text is about children and the space they occupy in their everyday lives, that is, the physical area where they spend their lives in the city. Dialoguing with authors working on the interfaces involving children, childhood and urban spaces, this book presents a contribution to these fields from the area of Children's Geography. The considerations presented here are based on the assumption that space cannot be separated from life, and on the refusal to accept a logic according to which human trajectories on Earth are linear paths set in a chronological sequence. The notion of geographical spaces as an expression built on life, and on places where life begins, embraces children's universe and makes it part of a dialectic process in which life and space are interwined. Therefore, talking about Children's Geography, and interpreting childhood from the perspective of the encounter allowed by the geographical spaces, is accepting children as a potential presence in our lives and as explicit subjects of enunciation acting under specific circunstances of time and space, and inserted into the political, symbolic and material dimensions of our society.

Keywords: Children. Childhood. Cities. Children's Geography.
\end{abstract}

\section{RESUMEN}

Este texto aborda a los niños y sus espacios cotidianos, más específicamente el espacio de sus vidas en las ciudades. Al dialogar con autores que abordan la interface niño, niñez y espacios urbanos, se busca traer contribuciones de la Geografía de la Infancia para el tema, se reconoce el espacio como indisociable de la vida y refuta la lógica que ha colocado las trayectorias humanas en la tierra como caminos lineales y en secuencia temporal cronológicamente concebida. La concepción de espacio geográfico como expresión construida en la vida y de donde la vida se origina abarca el universo infantil y lo coloca entre ese proceso dialéctico. Así, hablar en Geografía de la Infancia, leer la infancia, teniendo como sesgo de entrada ese encuentro que el espacio geográfico permite es, además de un significativo encuentro generacional, asumir a los niños con sus potenciales presencias en nuestras vidas y como sujetos explícitos de enunciaciones en el espacio y en el tiempo y que no están fuera de la dimensión política, tanto simbólica como material de las sociedades.

Palabras clave: Niños. Infancia. Ciudades. Geografía de la Infancia.

\footnotetext{
* Graduação em Geografia pela UFJF. Doutorado em Educação pela UFF. Pós-doutorado na Universidade de Siegen/Alemanha. Professor do Programa de Pós-Graduação em Educação da UFF e da UFJF. Pesquisador dos temas: Geografia da Infância, educação infantil, cartografia com crianças. <https://orcid. org/0000-0003-3510-8647>. E-mail: <jjanergeo@gmail.com>.

**Graduação e licenciatura em Geografia pela USP. Magister Artium-M.A. em Etnologia e Psicologia Social pela Ludwig-Maximilians-Universität de Munique/Alemanha. Doutorado em Geografia pela USP. Pós-doutorado em Geografia da Infância na UFF. Professora do Programa de Pós-Graduação em Educação da UnB. Pesquisadora dos temas: Geografia e infância, educação em contextos culturais específicos, ensino de Geografia nos anos iniciais da escolarização. <https://orcid.org/0000-0003-4878-3115>. E-mail: <lidia_f@uol.com.br>.
} 


\section{Primeiras palavras}

Era João Romão quem lhes fornecia tudo, tudo, até dinheiro adiantado, quando algum precisava. Por ali não se encontrava jornaleiro, cujo ordenado não fosse inteirinho parar às mãos do velhaco. E sobre este cobre, quase sempre emprestado aos tostões, cobrava juros de oito por cento ao mês, um pouco mais do que levava aos que garantiam a dívida com penhores de ouro ou prata.

Não obstante, as casinhas do cortiço, à proporção que se atamancavam, enchiam-se logo, sem mesmo dar tempo a que as tintas secassem. Havia grande avidez em alugá-las; aquele era o melhor ponto do bairro para a gente do trabalho. Os empregados da pedreira preferiam todos morar lá, porque ficavam a dois passos da obrigação (AZEVEDO, em O cortiço, 1997).

O romance $O$ cortiço, de Aluísio de Azevedo, publicado pela primeira vez no ano de 1890 , conta com diversas edições até o momento atual. Narra a vida de João Romão, comerciante português, morador do Rio de Janeiro do século XIX. A história de João Romão e de diversas outras personagens contextualiza a geografia urbana do Rio de Janeiro, apresenta uma descrição dos arranjos espaciais que configuravam essa cidade, marcada pela presença de cortiços e palacetes que se misturavam em uma cidade onde tudo se confluía.

Segundo o estudo clássico de Abreu (1997), o Rio de Janeiro, no século XIX, era uma cidade colonial, de pedestres, que iria passar por transformações intensas em seu formato urbano, configurando-se como um espaço estratificado em termos de classe social. Nas palavras do próprio autor:

Era também uma cidade em que a maioria da população era escrava. Quase que uma cidade de mercadorias. Poucos eram os trabalhadores livres, e reduzidíssima a elite administradora/militar/mercantil que lhe dirigia política e economicamente. A falta de meios de transporte coletivo e as necessidades de defesa faziam com que todos morassem relativamente próximos uns aos outros, a elite local diferenciando-se do restante da população mais pela forma - aparência de suas residências - do que pela localização das mesmas (ABREU, 1997, p. 27).

Abreu (1997) postula que a vinda da família real portuguesa, os investimentos estrangeiros e um conjunto de ações políticas locais iniciam um processo de modificação e transformação que lentamente irá esculpir uma paisagem na qual a forma-conteúdo evidencia a lógica de uma outra cidade. Uma metrópole que desponta no século XX, tipicamente capitalista: separada por classes, funções e redes de movimentos (principalmente transportes) que privilegiam mercadorias e determinados setores sociais.

Diversas intervenções irão compor as políticas que levarão a isso: estabelecimento de redes de transportes privilegiando algumas localidades, abertura de avenidas para circulação, desmonte de áreas consideradas insalubres, renovação sanitária e muitas outras propostas (ABREU, 1997). A lógica higienista irá fundamentar muitos dos argumentos dessa "necessária renovação urbana". Afinal, a cidade do Rio de Janeiro era um belo cartão-postal a se ver de longe, devido às péssimas condições sanitárias.

A proclamação da República consolidou o ideal de construção de um novo país, que incluía, entre os seus programas, a reestruturação da cidade do Rio de Janeiro como um dos seus pilares na formação de um imaginário social que pudesse consolidar o novo grupo no poder.

Assim, a capital federal passa por intensas modificações. As ruelas estreitas, típicas de uma cidade colonial, cedem lugar para amplas avenidas, cortiços são banidos em nome da higiene, novas lojas são erguidas seguindo os padrões dos boulevards franceses, as ruas, os bairros são renomeados, substituindo antigas nomenclaturas populares por nomes "oficiais". Essa intensa campanha de saneamento urbano busca erradicar os males tropicais, como varíola, peste, febre amarela e muitos outros que precisam ser eliminados, sedimentando as propostas higienistas que se fortaleciam. Populações inteiras são deslocadas, novos símbolos urbanos são erguidos nas paisagens:

A mais importante, em termos de transformação da forma urbana, foi sem dúvida a construção da Avenida Central (atual Rio Branco) para cuja abertura foram demolidas 'duas ou três mil casas, muitas com famílias numerosas', custando as desapropriações ao Governo Federal a quantia de 26.456:638\$01961*. Esta avenida era, sem dúvida, o complemento natural de duas outras grandes obras que se realizavam na cidade, ou seja, a Avenida Beira Mar (pela administração Passos) e o novo porto do Rio de Janeiro (a cargo da União). Decorria também da necessidade do capital e dos valores da época de se expressarem simbolicamente no espaço, razão porque, após a sua inauguração, em 15/11/1905, 'as melhores casas comerciais foram ali instaladas; os jornais construíram seus prédios monumentais e as grandes companhias, clubes, hotéis e vários edifícios do governo (Escola de Belas Artes, Biblioteca Nacional, Supremo Tribunal, Teatro Municipal, Palácio Monroe) foram nela localizados' (ABREU, 1997, p. 59).

Essas modificações tornam a cidade do Rio de Janeiro um estilhaço espacial do território brasileiro que buscava se assemelhar a uma porção da Europa nos trópicos do 
hemisfério sul, símbolo de "progresso e modernidade", estandarte de uma nova época e de um novo grupo no poder.

Talvez o exemplo mais significativo desse processo possa ser o desmonte do Morro do Castelo, completamente varrido no ano de 1921, na gestão da prefeitura de Carlos Sampaio. Considerado um morro apinhado de cortiços e casarões antigos, que impedia a circulação de ventos e bons ares na cidade, além de ser responsável por enchentes e mau cheiros, constituía, portanto, um lócus a ser erradicado.

Porém, por trás dos ares de modernidade, a exclusão permanecia e ampliava-se: as novas mudanças não eram para todos. Os menos abastados eram expulsos do novo espaço erguido, deslocando-se para áreas menos nobres, iniciando-se uma especialização do espaço urbano que passa a ser fatiado, segundo as condições econômicas e sociais. A lógica de uma cidade capitalista se desenhava e se tornava clara, marcada por profundas segmentações do sítio urbano, separando classes e funções.

No Brasil, a construção da nova capital federal, a cidade de Brasília, na década de 1950, ergue no espaço uma cidade pretensamente "pronta" dentro dessa lógica. Vesentine (1986) afirma que a futura capital foi pensada como um marco que separaria o Brasil agrário-exportador do Brasil urbano-industrial, com a construção simbólica da superação do "atraso" ligado à lógica das relações presentes naquilo que era conhecido e apresentado como "sertão". Este, um termo advindo de "desertão", que trazia, em seu bojo, todo um imaginário ligado ao rural e, portanto, ao arcaico. Ilustra-se esse viés de análise com a declaração:

\begin{abstract}
A impressão que eu tinha, contemplando aquele cenário grandioso, mas órfão de tudo, era idêntica à que havia experimentado por ocasião de uma viagem que fizera à cidade de Iturama, na ponta extrema do Triângulo Mineiro, logo que assumi o governo de Minas Gerais. A diferença entre os dois cenários era apenas de natureza humana. Em Iturama, havia ruas, casas, igrejas, gente morando sob os telhados que ameaçavam ruir. No Planalto Central, não se via vivalma. Era a terra e o cerrado. E, sobre ambos, o céu mais lindo do mundo. Entretanto, o espetáculo de desolação nos dois locais era o mesmo. Pedaços perdidos do Brasil, sacrificados pela miséria e falta de transportes (KUBITSCHEK, 2000, p. 33).
\end{abstract}

Toda a construção simbólica e imagética impressa nessa declaração aponta para uma das questões mais importantes na mudança da capital: a ideia de que o modo de vida da costa brasileira deveria atingir o interior e dar o tom do que seria a imagem do Brasil da segunda metade do século XX. A bala de prata para a superação desse modo de vida estava vinculada à industrialização do país, portadora do ideal de modernidade que se perseguia.
Brasília é, então, concebida e construída em função das novas lógicas de circulação. Apostando no sucesso da indústria automobilística, inaugura-se um plano urbanístico no qual "[...] a rua deve ceder seu lugar às vias expressas, adequadas ao automóvel e à rápida circulação" (VESENTINE, 1986, p. 151). Para o autor, esse plano urbanístico traz "[...] em sua concepção o louvor à autoridade, à hierarquia, à funcionalidade técnica [...]" (VESENTINE, 1986, p. 148). Assim, a cidade é construída em função do automóvel que se apresenta como ícone desses novos tempos. A arquitetura moderna é a lógica da cidade funcional, organizada para atender à demanda do capital, com poucos espaços para os pedestres, mas com amplas avenidas com circulação à velocidade de 60 ou $80 \mathrm{~km}$ por hora, no seio da cidade nascente.

Entretanto, a disputa entre a cidade que nasce para abrigar a modernidade e a realidade brasileira marcada pelo subdesenvolvimento e pela iniquidade deixa um rastro de segregação espacial, desigualdade e autoritarismo, que denota, uma vez mais, a "submissão dos trabalhadores ao capital, submissão da natureza à técnica capitalista" (VESENTINE, 1986, p. 149).

Brasília, capital do Brasil, completou 57 anos em abril de 2017. A arquitetura arrojada sobre "a calma severa majestosa" do vale, como descreveu o botânico Glaziou, no relatório da segunda Missão Cruls (2003), promete aos inúmeros visitantes a sensação de estar em uma civitas e a seus moradores uma vida generosa e de boa qualidade. Haja vista a lógica da cidade jardim, a sensação de se viver em uma cidade pequena, proporcionada pela estruturação das superquadras e pelo discurso de aproximação das pessoas de diferentes classes sociais e diferentes âmbitos culturais.

A cidade, promessa de um país moderno, não se concretiza na prática. Desde o início, percebe-se a dificuldade em abrigar a massa de trabalhadores da construção civil que veio a Brasília construir o sonho, sonhado por todos os brasileiros, mas levado a cabo por um enorme contingente de trabalhadores braçais, que se submeteu a jornadas extenuantes de trabalho, com muitos riscos de acidentes.

Como disse Lúcio Costa, em relatório da década de 1980, "a arquitetura não transforma a sociedade". Assim, Brasília configura-se como uma cidade em que o moderno convive com o arcaico de forma explícita. Tombada como Patrimônio da Humanidade, é marcada pela segregação espacial, pela exclusão dos trabalhadores que a construíram e pelo que se denomina (embora indevidamente) "Plano Piloto".

O arquiteto Jan Ghel (2017, p.1) ilustra essa dicotomia, denominando-a "Síndrome de Brasília" e apontando-a como significativa falência do movimento modernista: 
Minha conclusão sobre aqueles anos é que o movimento moderno disse adeus à preocupação com as pessoas. Por sua vez, havia uma preocupação com o homem moderno, para o qual a forma seguia a função. $\mathrm{O}$ movimento moderno também disse adeus à escala humana, porque, de repente, em vez de criar espaços, decidimos criar edifícios individuais e os edifícios ficaram cada vez maiores. No começo, projetávamos espaços, agora criamos os espaços que sobram entre os edifícios e a noção mais próxima de escala humana desapareceu totalmente. $\mathrm{Na}$ realidade, diria que os arquitetos e planejadores do movimento moderno estavam completamente enganados sobre o que era uma boa escala.

Desse modo, utilizando as transformações urbanas do Rio de Janeiro, interpretando a configuração espacial que se inaugura com Brasília e anuindo que esse processo de transformação se presentifica em diversas cidades do Brasil e do mundo e se apresenta de forma mais aguda nas regiões periféricas do planeta, cabe um olhar para o território nacional, na perspectiva de retratar como esse fenômeno se apresenta (Figura 1).
Observando o mapa das aglomerações urbanas, identifica-se que o modo de vida citadino é um fenômeno que se universaliza ou, no mínimo, tem ampliado e/ou condicionado significativamente outros modos de vida. Indaga-se, então, sobre a presença das crianças nesses espaços.

Reconhece-se a necessidade de compreender as infâncias e a vida das crianças a partir dessas produções socioespaciais, pois estar aqui ou em outra localidade do planeta faz toda a diferença, quando se pensa na produção da própria diferença e da diversidade de infância. O espaço geográfico é um elemento fundamental nesse processo. É um dos entrecortes que não pode ser ignorado.

Essa pergunta se faz significativa, ainda, porque, na Geografia, a forma e o conteúdo espacial são dois componentes indissociáveis e vestígios dos processos que ocorrem na configuração dos espaços, das paisagens e dos territórios, reveladores de como os diferentes grupos se relacionam com as infâncias que também se constituem nessas localidades. Acessar o espaço geográfico, suas expressões e manifestações é acessar a vida que cotidiana

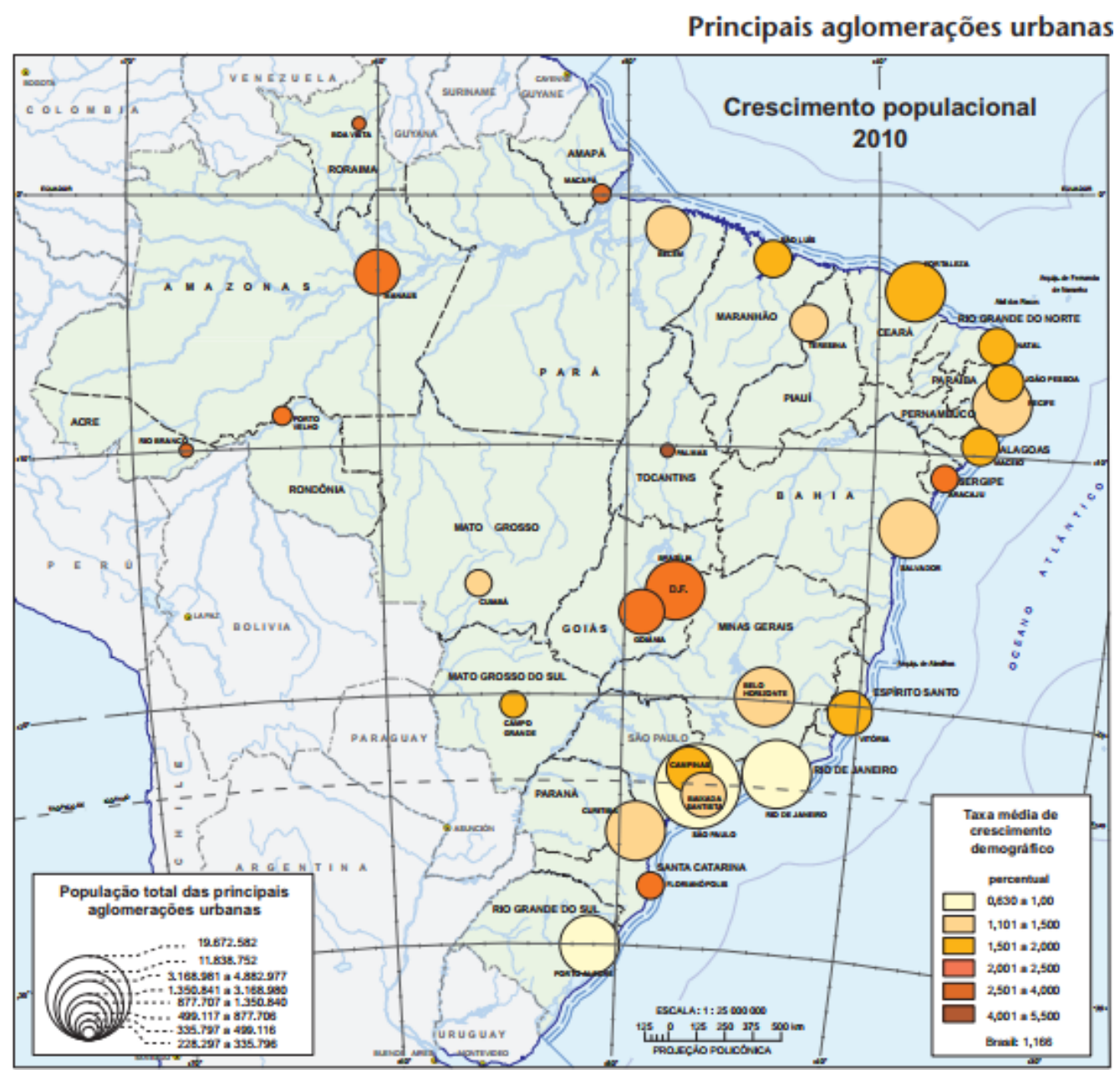

Figura 1. Atlas do Censo Demográfico 2010 - IBGE Urbanização Fonte: IBGE (2010). 
e politicamente ocorre e possibilita uma leitura geográfica dos eventos sociais. É nesse sentido que se pode falar em uma Geografia da Infância (LOPES; VASCONCELLOS, 2015), em uma Geografia das Crianças, em paisagens de infâncias, como abordado por Lopes (s. d.):

No campo da infância a paisagem aparece como uma força reveladora, pois as sociedades, ao reservarem um lugar social para suas crianças, criam formas, elaboram artefatos que materializam as concepções de infância pré-existentes nesse contexto social, construindo o que denominamos 'paisagens de infância' [...].

$\mathrm{O}$ acesso aos diferentes estratos dessas paisagens torna possível cartografar não só as concepções de infância que foram sistematizadas ao longo de sua produção - e se constituíram como formas e eventos no espaço - como também nos possibilitam acessar os diferentes agentes que a produziram, inclusive a participação (ou não) das crianças nesse processo. ${ }^{1}$

Este texto busca trazer contribuições dessa área para pensar as crianças e as cidades. Em um país cuja capital já nasce como uma cidade segmentada, finalizada, com grandes metrópoles, e cuja maior parte da população atual reside em áreas urbanas, as práticas socioespaciais constituem um elemento primordial nesse binômio.

\section{PALAVRAS INTERMEDIÁRIAS: GEOGRAFIAS DA INFÂNCIA}

Martha Muchow estudou como as crianças, em um bairro de classe operária, usaram sua criatividade para transformar o quarteirão e as ruas em seus próprios espaços de vida. Muchow escolheu [...] uma parte da cidade de Hamburgo como seu local de pesquisa. [...] O estudo documenta um pedaço da história da infância urbana, vista de baixo, usando uma perspectiva sensível e participativa (ZINNECKER; SCHONING, prefácio da edição de 1978).

$\mathrm{O}$ estudo da presença das crianças na cidade tem sido um dos focos das pesquisas dos autores deste artigo. Entre os trabalhos desenvolvidos, ${ }^{2}$ há um esforço acadêmico para sistematizar autores que têm se dedicado aos estudos envolvendo as crianças e seus espaços geográficos cotidianos, investigação que ocorre no âmbito da própria Geografia e em outros campos de conhecimento.

\footnotetext{
${ }^{1}$ Fonte: <www.geografiadainfância.blogspot.com.br>. Acesso em: 01 jul. 2017.

2 Refere-se à ação do Grupo de Pesquisa e Estudo em Geografia da Infância (Grupegi/CNPq), com sede na Universidade Federal Fluminense, mas que se estende em rede para a Universidade Federal de Juiz de Fora e para a Universidade de Brasília.
}

Uma das primeiras referências encontradas até o momento foi a pesquisa concebida por Marta Muchow, ${ }^{3}$ alemã, nascida no dia 25 de setembro de 1892, na cidade de Hamburgo, Alemanha, e falecida no ano de 1933, mais precisamente no dia 27 do mesmo mês de seu nascimento, vítima de suicídio, pressionada pelas ações do regime nazista.

O livro Der Lebensraum des Großstadtkindes (publicado em inglês com o título The life space of urban child) encontra-se em tradução para o português. Uma versão livre poderia ter o título próximo a $O$ espaço da vida da criança na cidade grande ou $O$ espaço de vida da criança na metrópole. A obra foi publicada após sua morte pelo seu irmão, Hans Heinrich Muchow, no ano de 1935.

Lopes e Fichtner apresentam uma descrição do conteúdo do texto (no prelo), o que dá uma ideia da amplitude e da importância desse trabalho:

\begin{abstract}
O livro de Muchow (Muchow und Muchow, 2012) é dividido em três capítulos, que descrevem a perspectiva de estudo: o primeiro intitulado Der Lebensraum als 'Raum, in dem das Kind lebt ( $\mathrm{O}$ espaço de vida como 'espaço no qual a criança vive'), o segundo Der Lebensraum als 'Raum, den das Kind erlebt (O espaço de vida como o 'espaço em que vivencia') e o terceiro Der Lebensraum als 'Raum, den das Kind lebt' (O espaço de vida como o 'espaço que a criança vive'). Todos esses capítulos apresentam subdivisões internas que detalham os momentos da investigação, aparecendo, ao final, as conclusões.
\end{abstract}

São os próprios autores, ao final, que apontam o quanto essa pesquisa, ocorrida no início do século XX, é contemporânea:

Como pode ser percebido, os postulados presentes [...] no livro poderiam estar presentes em qualquer obra atual que preconiza sobre o protagonismo e a participação das crianças, suas lógicas e formas próprias de ser e estar no espaço. Trabalhos posteriores, que acabaram tendo grande impacto nos estudos da percepção espacial e ambiental, acabaram se tornando mais conhecidos. Porém, essas ideias, que já haviam sido esboçadas por Muchow anos antes, acabaram, talvez por barreiras da língua ou devido a outros fatores, tendo ficado restritas ao seu próprio país" (LOPES; FICHTNER, 2017).

Na área específica da Geografia, faz-se necessário destacar uma importante pesquisa do geógrafo Bill Bunge,

\footnotetext{
${ }^{3}$ Esse encontro só foi possível com a ajuda intensa do professor Bernard Fichtner, que não só presenteou o grupo com o livro Der Lebensraum des Großstadtkindes, em sua última versão, mas também ajudou na sua produção e tradução para o português. Agradecimentos ao professor.
} 
realizada em comunidades negras de Detroit (nomeada de The Detroit Geographic Expedition), no final dos anos 1960 e início de 1970; portanto, posterior aos trabalhos de Muchow na Alemanha. O geógrafo compilou um estudo com as crianças dessas comunidades, a partir de observação etnográfica, e confeccionou mapas sobre o alto número de mortes por atropelamentos que envolviam as crianças e os carros, com o título Where commuters run over black children on the pointes-downtown track.

Porém, abarcando os pressupostos da Geografia da Infância, encontram-se seus referenciais identificados com os teóricos da Geografia Cultural ancorada na discussão proposta por Armand Frémont, nos anos 1970, sobre espaço vivido, interpretado por Claval (2003, p. 11) como "[...] a consciência da significação espacial que adquire a experiência dos lugares para aqueles que os habitam".

Essa abordagem de base filosófico-fenomenológica, que sustenta grande parte dos estudos sobre Geografia da Infância, foi posteriormente atravessada por autores do campo do conhecimento sociológico, que passaram, a partir da década de 1990, a defender a infância como uma construção social que deve ser compreendida com outras variáveis, como o gênero, a classe e a etnicidade; e, ainda, em sua condição de sujeitos atuantes na produção da sociedade.

Os estudos de Jens Qvortrup (obras diversas) e de autores como Alan Prout (obras diversas), Aliison James (obras diversas), Willian Corsaro (obras diversas), Regine Sirotá (obras diversas), Julie Delalande (obras diversas), Manuel Sarmento (obras diversas) e outros também compõem essa área. Salienta-se neste texto a contribuição do primeiro que, ao propor uma análise que considera as forças sociais, ou melhor, a variável estrutural e seus macroparâmetros como importantes elementos na pesquisa envolvendo o universo infantil, defende que as crianças têm um papel bastante ativo na sociedade em que estão inseridas. Influenciam e são influenciadas, ocupam posição na divisão social do trabalho e desenvolvem, em princípio, suas tarefas escolares, entre outras atividades, dependendo do seu universo social e cultural.

Assim, percebe-se uma Geografia da Infância e uma Geografia das Crianças que se estrutura na interface com a própria Geografia, mas também em relação a outros campos de conhecimentos que exprimem o sentido interdisciplinar defendido por Prout (2010).

Dialoga-se, dessa forma, com autores que advogam contra a tentativa de normalização e normatização dessas infâncias e de seus tempos/espaços que, na verdade, são os que as constituem. Além disso, salienta-se o fato de não se trabalhar com a concepção de infância na perspectiva do vir a ser, nem busca-se enquadrar esses sujeitos em um modelo prévio de infância ou mesmo de família ou de escola, em tipologias desenvolvimentistas que se expressam em abordagens e conhecimentos canônicos. Reconhece-se a infância em sua dimensão plural, nas forças constitutivas de agentes e vetores sociais que trazem as crianças em sua inserção territorial (LOPES; VASCONCELLOS, 2005) nas relações com adultos, instituições, normas e atividades de criação. Constantes inacabamentos e diferenças, todos como vetores para pensar as infâncias e as crianças nas cidades.

Posto isso, concorda-se com Aitken (2014), que, atento à discussão sobre a diversidade de infâncias, alerta para o risco de se conceber a ideia de "uma infância normal" em "espaços normais". Para o autor, essa concepção estaria ancorada nas premissas da inocência, do lúdico, do cuidado, com foco nos processos educacionais, no primeiro caso, e em modelos de famílias nucleares e expandidas vivendo assistidas por comunidades e pelo Estado (AITKEN, 2014). Segundo ele, o papel da Geografia, nesse cenário, é justamente discutir e contestar a proliferação de uma visão hegemônica que tenderia a encobrir as disparidades. "Crianças são inconscientemente afetadas pelas disparidades espaciais e desigualdades sociais" (AITKEN, 2014, p. 139). Sobre isso, afirma ainda que "[...] os conjuntos societários são sempre geograficamente variáveis" (AITKEN, 2014, p. 133). Esses "conjuntos societários", são, portanto, instáveis em suas historicidades.

Propõe-se a abordagem do tema Geografia da Infância a partir dessas reflexões de Aitken (2014) em diálogo com Lefebvre (1991), Massey (2015) e Harvey (2008), que trazem a discussão espacial, com ênfase nas abordagens sobre cidade e cidadania a partir do viés político. Confronta-se a ideia de normalidade e, contextualiza-se, como ensina Aitken (2014), os direitos das crianças em diferentes contextos e suas competências em uma variedade de espaços, sem juízo de valor sobre estar ou não "fora do lugar", fazendo ou não "coisas que não correspondam ao universo infantil".

Como tônica dessa discussão, elencam-se os direitos infantis e corrobora-se a ideia de Aitken, segundo o qual parte da discussão sobre o direito da criança passa pela compreensão da forma como os jovens "[...] imaginam, criam, habitam e produzem espaços" (2014, p. 133).

Nessa mesma linha de reflexão, tem-se a abordagem de Harvey (2008), que aponta para o uso político do espaço. Em seu artigo The right to the city (2008), o autor traz importante debate sobre o espaço urbano em sua dimensão política, retoma a lógica dos movimentos sociais, desde os franceses, a partir da reforma urbana levada a cabo por Haussmann, em Paris, desde os anos 50 do século XIX até os movimentos por direitos civis nos Estados Unidos, protagonizados pelas minorias, em especial pelos moradores suburbanos nova-iorquinos, 
afetados pelas reformas urbanas de Robert Moses na década de 1960.

$\mathrm{O}$ autor, na epígrafe de seu artigo, apresenta a confluência /conexão entre o mundo e a vida e aponta para a necessidade de se olhar a cidade e a vida na cidade como paradigmas de construções de ideias de mundo e de vida, respaldadas na perspectiva de "[...] construir e reconstruir as cidades como importante direito humano, [entendendo que] a liberdade de fazer e refazer nossas cidades e a nós mesmos é um dos mais preciosos mas ainda mais negligenciados dos nossos direitos humanos" (HARVEY, 2008, p. 23):

The question of what kind of city we want cannot be divorced from that of what kind of social ties, relationship to nature, lifestyles, technologies and aesthetic values we desire. The right to the city is far more than the individual liberty to access urban resources: it is a right to change ourselves by changing the city. It is, moreover, a common rather than an individual right since this transformation inevitably depends upon the exercise of a collective power to reshape the processes of urbanization. The freedom to make and remake our cities and ourselves is, I want to argue, one of the most precious yet most neglected of our human rights (HARVEY, 2008, p. 23).

Ainda nessa linha de reflexão, são caras as contribuições de Jane Jacobs $(2011)^{4}$, com sua obra Morte e vida de grandes cidades, que aponta, acima de tudo, a preocupação com a densidade populacional das cidades, a necessidade de que se ocupem os espaços públicos, a preocupação com que a cidade seja apropriada, criada e usada por todos e para todos. Enfim, essa abordagem corrobora a concepção de cidade, permitindo que se vislumbre nela a infância.

Retoma-se Harvey (2008), que remete à necessidade de reestabelecimento de diálogo com a obra de Lefebvre (1991), em especial no seu diálogo sobre o "direito à cidade", obra seminal que aponta para a necessidade de "[...] conceber uma estratégia do conhecimento, inseparável da estratégia política, ainda que distinta dela" (LEFEBVRE, 1991, apresentação).

Para pensar as questões ligadas às Geografia(s) da(s) Infância(s), reafirma-se a relevância do espaço/tempo na configuração da infância, ou seja, a infância de que se fala, narrada em sua condição cronotópica (BAKHTIN, 2014), que marca profundamente as fronteiras e a alteridade das crianças no mundo. Aponta-se a necessidade de localização dessas múltiplas infâncias no tempo e no espaço, conectando as vivências infantis aos contextos culturais e considerando o papel da criança na produção

\footnotetext{
4 Obra original de 1961, com o título The death and life of great American cities.
}

do espaço e suas linguagens espaciais. Para Lopes (2008, p.12), "[...] a noção espacial, como parte integrante dos sujeitos, seria assim uma noção social, uma construção semiótica, constituída a partir do contexto cultural no qual se está inserido".

Espaço geográfico, categoria de análise primordial da Geografia, refere-se à unidade contínua entre a sociedade e a base física. Assim, reconhece-se a vinculação entre espaço e cultura na configuração de alteridades e diferenças a partir de um universo semiótico, ancorado nos campos de sentido e significado que os seres humanos constroem na e pela relação com seu espaço e com o universo material que os circunda.

É importante salientar que, na abordagem a respeito do espaço, concorda-se com Aitken (2014) sobre o risco de se concentrar a análise espacial apenas sob a perspectiva fenomenológica que, do seu ponto de vista, pode correr o risco de ser apolítica, já que

[...] concentra sua observação no sentido de pertencimento, de afeto e genius loci, mas, do que se trata efetivamente é de pensar nas forças que produzem esse espaço, para quem eles são produzidos, Pessoas e/ou eventos e por que são mantidos. Muitas vezes pensamos pouco nos modos como os espaços são produzidos e criados (AITKEN, 2014, p. 134).

Para o autor, sob o ponto de vista da Geografia Contemporânea, na abordagem dos direitos infantis, a perspectiva de que "[...] o espaço é produzido, é palpável e totalmente político" é reforçada (AITKEN, 2014, p. 134). Outro ponto abordado por Aitken diz respeito à crença no espaço como imutável, que confina as crianças e os jovens aos locais prescritos pelos adultos devido à preocupação com o seu "bem-estar".

Nesse sentido, a abordagem de Massey (2015) traz a dimensão do "espaço como algo sempre em construção", "sempre no processo de fazer-se" e como "simultaneidade de estórias-até-agora". Para a autora, essa ideia de espaço como algo aberto reforça a dimensão política referida por Aitken e recoloca o campo de disputas e da política como a possibilidade de fazer diferente, ou seja, de abertura para outras construções possíveis.

Massey (2015) propõe que, como forma política de ser e estar no mundo, recoloque-se a ideia da globalização como projeto, de modo que não seja encarada em sua perspectiva de inevitabilidade e de construção de espaços homogeneizados e hegemonizados, mas, fugindo dessa perspectiva, assuma-se que "[...] isso não é uma descrição do mundo como ele é, mas uma imagem através da qual o mundo está sendo feito" (MASSEY, 2015, p.24).

Dessa forma, estabelece-se o diálogo com autores que tratam da globalização em seu caráter de mito ou fábula (MORAES, 2011; SANTOS, 2000) e em sua penetração 
nos diferentes locais do planeta, tanto no plano macro como no nível da organização cotidiana. Seja em seus processos de normatização e mercantilização do território, seja no seu papel na mudança dos padrões de consumo, busca-se apreender as formas de diálogo e os mecanismos de transformação ao alcance das mãos, em um cenário de disputa de narrativas e de competição desigual com os fortes aparatos midiáticos.

Assim, a interpretação do que afirma Massey sobre a globalização permite enfatizar que esses espaços devem ser entendidos em sua própria trajetória, em suas especificidades e "[...] multiplicidade de trilhas percorridas e, por isso, traçam seus caminhos para o futuro informado pela sociedade que lhes confere especificidade" (MASSEY, 2015, p. 24).

Por fim, trabalhando-se com a perspectiva do espaço como algo sempre em construção e como um produto de relações entre seus múltiplos atores, também vislumbrase essa infância na sua perspectiva de agency, sempre no processo de se fazer.

Parece oportuno lembrar que o espaço e o tempo não são existências descoladas das vivências humanas, mas representam trajetórias constituídas ao longo da filogênese humana em sua imersão social, que emergem na ontogênese, em constantes processos de criação.

Com isso, reafirmam-se as diferenças das infâncias e suas correlações com as diferenças no espaço, assumindo um caráter polissêmico, mas não distanciado das suas contradições sociais, ao mesmo tempo em que se abre para o espaço das diferenças. Um jogo de palavras que marca a vivência como alteridade.

Aitken (2014), ao trazer a presença da juventude no espaço, assinala que este não representa simplesmente os lugares que ajudam a entender um contexto particular de moradia dos jovens. Significa, sim, aqueles que são ativamente criados pelos jovens e suas relações com o mundo, incluindo toda a gama de relações estabelecidas sobre a tomada do espaço público de volta para a esfera do público, sobre o direito à manifestação, entre outros. $\mathrm{A}$ partir dessa compreensão, Aitken (2014, p. 134) reafirma que se trata mais " [...] de construir o direito à alteridade, à diferença, do que propriamente buscar a igualdade, a própria discussão do trabalho, da segurança, do direito à cidade, pode significar questões muito específicas em cada um dos casos, quando se trabalha na perspectiva da infância". 5

\footnotetext{
5 A história mundial e a brasileira expõem movimentos da juventude que poderiam estar em acordo com os postulados do autor. No ano de 2016 , no Brasil, por exemplo, centenas de jovens, em várias partes do país, ocuparam escolas e universidades, contrários às políticas implantadas pelo governo federal.
}

\section{PARA CONTINUAR AS PALAVRAS E NAS PALAVRAS}

\begin{abstract}
Ateneu era o grande colégio da época. Afamado por um sistema de nutrido reclame, mantido por um diretor que de tempos a tempos reformava o estabelecimento, pintando-o jeitosamente de novidade, como os negociantes que liquidam para recomeçar com artigos de última remessa; o Ateneu desde muito tinha consolidado crédito na preferência dos pais, sem levar em conta a simpatia da meninada, a cercar de aclamações o bombo vistoso dos anúncios [...].

Transformara-se em anfiteatro uma das grandes salas da frente do edifício, exatamente a que servia de capela; paredes estucadas de suntuosos relevos, e o teto aprofundado em largo medalhão, de magistral pintura, onde uma aberta de céu azul despenhava aos cachos deliciosos anjinhos, ostentando atrevimentos róseos de carne, agitando os minúsculos pés e as mãozinhas, desatando fitas de gaza no ar. Desarmado o oratório, construíram-se bancadas circulares, que encobriam o luxo das paredes [...].

O Ateneu estava situado no Rio Comprido, extremo ao chegar aos morros. As eminências de sombria pedra e a vegetação selvática debruçavam sobre o edifício um crepúsculo de melancolia, resistente ao próprio sol a pino dos meios-dias de novembro. Esta melancolia era um plágio ao detestável pavor monacal de outra casa de educação, o negro Caraça de Minas (POMPÉIA, Raul, em O Ateneu, 1996).
\end{abstract}

Abriu-se este texto com a clássica obra de Aluísio Azevedo, uma narrativa de onde emerge a vida cotidiana do Rio de Janeiro do século XIX, evidenciando um espaço urbano marcado por diferenciadas formas e movimentos em sua paisagem. Buscando continuar nas palavras e na infinitude e inacabamento da vivência humana no espaço e do espaço na vivência humana, reporta-se a outro clássico da literatura brasileira: O Ateneu, de Raul Pompéia.

Sérgio, personagem central dessa obra, é um jovem interno em um dos colégios mais prestigiados pela elite carioca do, também, então século XIX. Mas O Ateneu, nome da instituição dirigida pelo pedagogo Sr. Aristarco, apresenta um grande protagonismo, sendo o lócus dos acontecimentos e relações de todos que por ali circulam e transitam por extensões de espaço e tempo que vão além desse local. A obra traz um marco, uma forma no espaço que se torna um dos centros de vivência de crianças e jovens: as escolas.

Bakhtin (obras diversas) ensinou a inexequibilidade de pensar a vida sem a experiência estética e as fronteiras possíveis que surgem nesse encontro. Reconhecendo a dimensão irrepetível da existência humana e a impossibilidade do acabamento da vida, encontra na arte, na literatura e em outras expressões humanas a refração potente para cotejar indícios sociais. Nessa perspectiva, a paisagem, o território, o lugar e tudo que composiciona 
o espaço geográfico no mundo são linguagens que permitem a entrada e o diálogo com a vida. O Ateneu, $O$ cortiço e diversas outras narrativas não são ecos de uma temporalidade, de uma espacialidade, mas traços cronotópicos (BAKHTIN, 2014) que formam as fronteiras de alteridade com o outro.

Isso remonta a tudo dito até este momento: o reconhecimento do espaço como indissociável da vida e a negação de uma lógica que colocou as trajetórias humanas na Terra como caminhos lineares e temporalizados cronologicamente. Todo espaço geográfico é uma expressão construída na vida e de onde a vida se origina, relação da qual as crianças não estão fora.

Por isso, falar em Geografia da Infância, ler a infância, tendo como viés de entrada esse encontro que o espaço geográfico permite, é, para além de um significativo encontro geracional, assumir as crianças com suas potenciais presenças e como sujeitos explícitos de enunciações no espaço e no tempo e que não estão fora da dimensão política, tanto simbólica quanto material das sociedades.

Paisagens de infância, como demarcações espaciais, representam formas-conteúdos que, conjugadas com as demais dimensões paisagísticas, são cronotopos (BAKHTIN, 2014) enunciativos. Isto é, postos de partida para acessar a rede de significações que fala das crianças nos espaços urbanos (e em outros espaços), cuja produção e organização são marcadas por diferenciados níveis e extensões, colocando a escala como um componente desse processo.

As crianças estão nas cidades. Mesmo que invisibilizadas por muitas ações/não ações, elas estão aí, nos metrôs, nas ruas, nos carros, nas escolas, nas casas, nos sinais, nos abrigos, nas calçadas, nas praças, nos parques, nas praias, nos jardins. Mas são todas crianças territorializadas espacialmente e que vivem o jugo de seus territórios e enraizamentos (econômicos e muitos outros) no embate das políticas econômicas e sociais.

Negar o espaço como dimensão fundante da infância e das crianças é negar uma das facetas da sociedade, olhar o espaço para além de sua dimensão de superfície, palco de apoio para as ações humanas, mas reconhecer sua importância na produção, sistematização e criação da vida e como lócus de vida. As crianças estão e são! Narrando:

\begin{abstract}
"Eu penso que isso tudo que tá acontecendo no Brasil, a gente que vai sofrer as consequências no futuro. E eu tô sendo uma das poucas que tô tendo a oportunidade de intervir e de lutar, então eu me sinto muito honrada. É esse o meu sentimento.” (G., 14 anos, entrevista, 2017) “É! Porque brincar, por exemplo, é um direito nosso; de criança! E direito não é coisa só de adulto, não é, tia?!" (I., 8 anos, entrevista, 2017)

"Hoje, por exemplo, a gente tá junto aqui falando sobre comunicação e sonhos que a gente tem de um novo espaço, de uma nova estrutural. A gente faz muito isso aqui." (D., 15 anos, entrevista, 2017)

"Hoje a gente tava brincando de política! Eu achei ótimo porque o meu partido é o do Brincar Bem! E eu sou o deputado que vou fazer uma lei pra gente sair pra brincar todo dia no parquinho lá da praça!” (P., 8 anos, entrevista, 2017)
\end{abstract}

Esses relatos, obtidos a partir das oficinas da Organização Não Governamental "Coletivo da Cidade", sistematizadas por Jackeline Corrêa de Sousa, em Trabalho de Conclusão de Curso, recentemente apresentado à Faculdade de Educação da Universidade de Brasília, com o título "Ressignificando o lugar: novos sentidos de educação, participação e protagonismo entre crianças e adolescentes da Cidade Estrutural - DF", permite considerar que esse caminho de reapropriação das cidades, de reencontro, de resistência, de reexistências tem possibilitado às crianças e adolescentes imaginar novas formas de socialização e de convívio na e com a cidade em sua diversidade. Como exemplo, apresentam-se as imagens de um jogo sobre a cidade, construído a partir de visitas de crianças e jovens que frequentam o Coletivo da Cidade em diferentes localidades do Distrito Federal. Com o levantamento dos problemas, de entrevistas, de visitas in loco, eles puderam sistematizar potenciais e ameaças à construção da cidade ideal. As imagens falam por si.

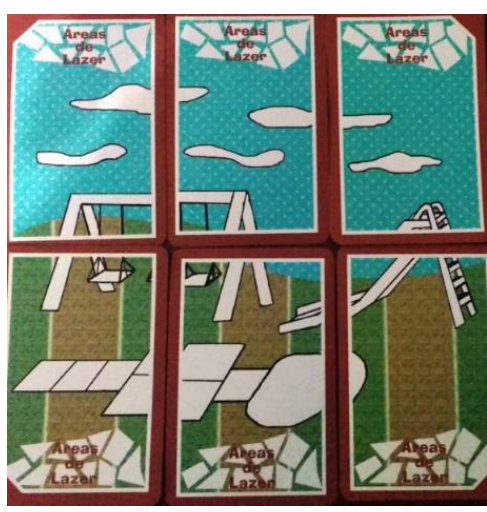

Figura 2. Ausência de lazer na cidade

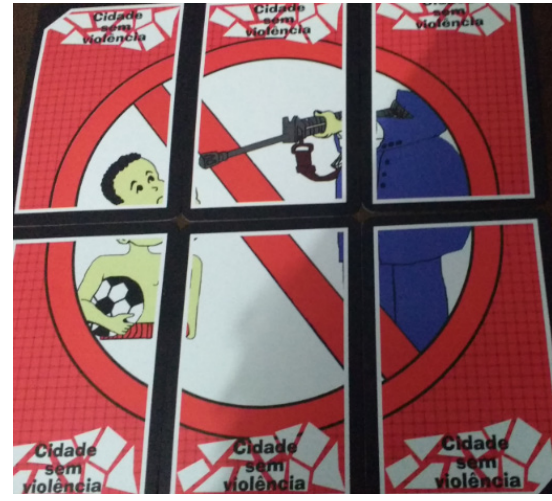

Figura 3. Violência na cidade
Nota: Entre as ausências enunciadas durante o trabalho de reconhecimento dos problemas das cidades, as áreas de lazer foram apontadas. Outro tema aventado pelos jovens foi a violência. Fonte: Imagens retiradas do jogo "Nossa cidade", elaborado pelo Inesc, em parceria com o Observatório da Criança e do Adolescente, do Coletivo da Cidade, Nossa Brasília, entre outros 


\section{REFERÊNCIAS}

ABREU, 1997. A evolução urbana do Rio de Janeiro. Rio de Janeiro: Iplan, 1997.

AITKEN, Stuart C. Children's rights: a critical geographic perspective. In: VANDERHOLE, W. et al. Routledge International Handbook of Children's Rights Studies. London, New York: T\&F Routledg, 2015. Disponível em: $<$ https://books.google.com.br/books?hl=pt-BR\&lr=\&id=Y6 WsBwAAQBAJ\&oi=fnd\&pg=PP1\&dq=AITKEN,+Stuart+ C. + Children $\%$ E2\%80\%99s+rights:+a+critical+geographic + perspective. \&ots $=$ KTBXIDgob5\&sig $=$ cqsatFRnEXEczN9F TSPxfkAElM $\# \mathrm{v}=$ onepage $\& \mathrm{q}=$ AITKEN $\% 2 \mathrm{C} \% 20$ Stuart $\% 20$ C. $\% 20$ Children $\%$ E $\% 80 \% 99$ s $\% 20$ rights $\% 3$ A $\% 20 a \% 20$ critical $\% 20$ geographic $\% 20$ perspective.\&f=false>. Acesso em: 24 fev. 2017.

AZEVEDO, Aluísio. O cortiço. 30. ed. São Paulo: Ática, 1997.

BAKHTIN, Mikail. Questões de literatura e estética: a teoria do romance. São Paulo: Hucitec, 2014.

CLAVAL, Paul. A geografia cultural. Florianópolis: UFSC, 2014.

CLAVAL, Paul. A evolução recente da geografia. Geosul, Florianópolis, v. 18, n. 35, p. 7-25, jan./jun. 2003.

CRULS, Luiz. Relatório Cruls. Brasília: Conselho Editorial do Senado Federal, 2003.

GEHL, Jan. Do chão, onde vivem as pessoas, Brasília é uma merda. Arch daily, 2017. Disponível em: <http:/www.archdaily. com.br/br/875009/jan-gehl-do-chao-onde-vivem-as-pessoasbrasilia-e-uma-merda?utm source=MyArchDaily\&utm medium $=$ book mark-show $>$. Acesso em: 12 jul. 2017.

HARVEY, David. The right to the city. New Left Review, n. 53, p. 23-40, Sept./Oct. 2008. Disponível em: <https:// newleftreview.org/II/53/david-harvey-the-right-to-the-city>. Acesso em: 27 fev. 2017.

IBGE. Atlas do Censo Demográfico: urbanização. IBGE, 2010. Disponível em: <http://biblioteca.ibge.gov.br/visualizacao/ livros/liv64529_cap6.pdf>. Acesso em: 12 jul. 2017.

JACOBS, Jane. Morte e vida de grandes cidades. São Paulo: Editora WMF Martins Fontes, 2011.

KUBITSCHEK, Juscelino. Por que construí Brasília. Brasília: Senado Federal, 2000.

LÉFÈBVRE, Henri. Lógica formal, lógica dialética, 6. ed. Rio de Janeiro: Civilização Brasileira, 1995.
LÉFÈBVRE, Henri. O direito à cidade. São Paulo: Moraes, 1991.

LOPES, Jader Janer; FICHTNER, Bernd. O espaço de vida da criança: contribuições dos estudos de Marta Muchow às crianças e suas espacialidades. R. Educ. Públ. Cuiabá, v. 26, n. 63, p. 755-774, set./dez. 2017.

LOPES, Jader Janer; VASCONCELLOS, Tânia. Geografia da Infância. Juiz de Fora: Feme Edições, 2015.

LOPES, Jader Janer; VASCONCELLOS, Tânia. Desenhando conceitos em Geografia da Infância. Disponível em: <http:// geografiadainfancia.blogspot.com.br/p/nossas-pesquisas. html>. Acesso em: 15 maio 2017.

MASSEY, Doreen B. Pelo espaço: uma nova política da espacialidade. Rio de Janeiro: Bertrand Brasil, 2015.

MORAES, Antônio Carlos. Robert de. Geografia histórica do Brasil: capitalismo, território e periferia. São Paulo: Annablume, 2011.

POMPÉIA, Raul. O Ateneu. 16. ed. São Paulo: Ática, 1996.

PROUT, Alan. Reconsiderando a nova Sociologia da Infância. Cadernos de Pesquisa, v. 40, n. 141, p. 729-750, set./dez. 2010.

QVORTRUP, Jens. Nove teses sobre a infânica como fenômeno social. Pro-Posições, v. 22, n. 1, p. 199-211, 1983.

SANTOS, Milton. Por uma outra globalização: do pensamento único à consciência universal. Rio de Janeiro: Record, 2000.

SOUSA, Jackeline Corrêa. Ressignificando o lugar: novos sentidos de educação, participação e protagonismo entre crianças e adolescentes da Cidade Estrutural - DF. 2017. 77 f. (Trabalho de Conclusão de Curso) - Faculdade de Educação, Universidade de Brasília, Brasília, 2017.

VESENTINE, José William. A capital da geopolítica. São Paulo: Ática, 1986.

Zinnecker, Jürgen; Schonig, Bruno von (Hrsg.). Martha Muchow, Hans Heinrich Muchow - Der Lebensraum des Großstadtkindes (1935). Bensheim: päd.-extra buchverlag, 1987.

Recebido em 27.04.2018

Aprovado em 04.07.2018

Endereço para correspondência:

Jader Janer Moreira Lopes

Rua Adalgisa Gonçalves Soares, 170 - Bairro São Pedro

36037-390 Juiz de Fora, MG, Brasil 